\title{
UTS Maximization in Solid State Joining Process for AA6082
}

\author{
Sumit jain ${ }^{1}$, Preety Rani ${ }^{2}$, Rajat gupta ${ }^{3}$, Neeraj Sharma $^{4}$ \\ ${ }^{1,2}$ (Department of Mechanical and Automation Engineering, HMR Institute of Technology And Management, \\ Delhi, India) \\ ${ }^{3(}$ Department of Mechanical Engineering, R.P. Inderaprastha Institute of Technology, Karnal, India) \\ ${ }^{4}$ Department of Mechanical Engineering, D.A.V. University, Jalandhar, India)
}

\begin{abstract}
This study focused on the ultimate tensile strength (UTS) maximization of solid state joining process i.e. friction stir welding (FSW) by using vertical milling machine on AA 6082-T6. In order to evaluate the effect of process parameters such as tool rotational speed, traverse speed and tool pin length on ultimate tensile strength of friction stir welded aluminum alloy 6082-T6, Taguchi parametric design and optimization approach was used. Through the Taguchi parametric design approach, the optimum levels of process parameters were determined. The results indicate that the rotational speed and welding speed are the significant parameters in deciding the tensile strength of the joint and the tool pin length is the least significant parameter in deciding the tensile strength of the joint.
\end{abstract}

Keywords - Aluminum alloy, friction stir welding, tensile strength, Taguchi Technique.

\section{INTRODUCTION}

Friction stir welding is a solid state welding which was developed by TWI (a research institute) in US. Friction stir welding is largely used in aerospace, marine, automotive and many other application in commercial field. In friction stir welding the two metal plates are welded together with the help a rotating non-consumable high strength with a profiled probe that extends from a cylindrical shoulder. The length of the probe should be less than thickness of the plates to be weld. And the plates are clamped in a special designed fixture to prevent the butted joint to force apart. Frictional heat is generated between the welding tool and the work pieces because of friction between them. This heat softens the material without reaching the melting point and allows traversing of the tool along the weld line. M. Ericsson et al. [1] determined whether the fatigue strength of AA 6082 using friction stir (FS) welds is influenced by the welding speed, and also to compare the fatigue results with results for conventional arc-welding methods: MIG-pulse and TIG. Adamowski et al. [2] analyzed the results of tests on the mechanical properties and micro-structural changes in Friction Stir Welds in the aluminum alloy 6082-T6 in function of varying process parameters. Patil et al. [3] investigated the effects of different welding speeds and tool pin profiles on the weld quality of AA6082-O aluminum. Tri-flutes and taper screw thread pin were used as tool pin profiles inthis research. The friction stir welded plates of AA6082-O by using the taper screw thread pin profile reaches the ultimate tensile strength of $92.30 \%$ of the base metal ultimate strength and \% elongation of $27.58 \%$. Babu et al. [4] investigated the effect of processing parameters on mechanical and micro-structural properties of aluminum alloy 6082-T6 Friction stir-welded (FSW) joints. The experimental results indicated that the process parameters have a significant effect on weld macrostructure and mechanical properties of joints. Scialpi et al. [5] studied the effect of different shoulder geometries on the mechanical and micro-structural properties of a friction stir welded joints. The process was used on $6082 \mathrm{~T} 6$ aluminum alloy in the thickness of $1.5 \mathrm{~mm}$. The three studied tools differed from shoulders with scroll and fillet, cavity and fillet, and only fillet. The effect of the three shoulder geometries was analyzed by visual inspection, macrograph, HV micro-hardness, bending test and transverse and longitudinal room temperature tensile test. The investigation results showed that, for thin sheets, the best joint has been welded by a shoulder with fillet and cavity. A number of researchers [6-13] worked on optimizations of process parameters.

\section{EXPERIMENTAL Procedure}

The experiments for welding were carried out on a universal vertical milling machine as shown in figure 1. The tool for welding was hold in the spindle of machine and the plates for welding were mounted in a fixture which was clamped on the table of the machine. Two aluminium alloy 6082-T6 plates of size 
$90 \mathrm{~mm} \times 60 \mathrm{~mm} \times 6 \mathrm{~mm}$ size plates were mounted on the fixture of vertical milling machine for making butt joint by using friction stir welding process as shown in fig. 1 and the chemical composition as well as mechanical properties were provided in table 1 . Given the Al-Mg-Si alloys are rather easily weld-able even with conventional techniques; it was decided to verify weld-ability of AA 6082-T6 alloy by the most possible range of process parameters.

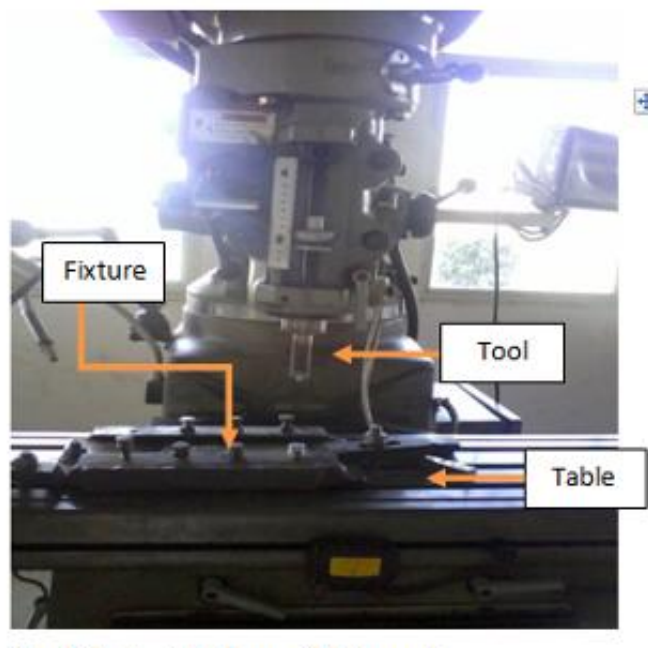

TABLE 1: Chemical Composition of AA 6082-T6

Fig. 1 Pictorial view of Universal Vertical Milling Machine

The tool for welding AA6082-T6 by FSW was made of high carbon steel. The tool was consist of tool shank, tool shoulder and tool pin. Tool shank was used to hold the tool on the spindle of vertical milling machine. Then tool pin was for producing heat due to friction and to stir the material during welding. Tool shoulder was used for producing extra welding heat and to cap the material during welding. For this reasearch tool shoulder diameter of $15 \mathrm{~cm}$ was used. For holding the tool on milling machine the shank diameter was made $17 \mathrm{~mm}$. and the pin length was used as parameter for welding AA6082-T6. The parameters which selected for this investigation were: tool rotation speed, transverse/welding speed and Tool pin length. The number of parameters and their levels are shown in table 2. Various experiments were conducted for optimize the response parameter (Ultimate tensile strength). Taguchi's robust design of experiments (DOE) methodology was used to plan the experiments statistically. Taguchi's robust design of experiments (DOE) methodology was used to plan the experiments statistically. L9 orthogonal array has come out as one of the possible solutions for designing the experiments. The levels for each factor during each trial are more conveniently expressed by means of experimenter's log sheet (refer Table 3).

The experimentation for the study undertaken consisted of nine trial runs results of ultimate tensile strength and $\mathrm{S} / \mathrm{N}$ ratio after welding as shown in Table 3.

TABLE II. Control variables and their levels

\begin{tabular}{|c|c|c|c|c|c|}
\hline S. No & Parameters & Levels & Level 1 & Level 2 & Level 3 \\
\hline A & Tool rotation speed & 3 & 1200 & 1950 & 3080 \\
\hline B & welding speed & 3 & 20 & 25 & 30 \\
\hline C & Tool pin length & 3 & 5.4 & 5.6 & 5.8 \\
\hline
\end{tabular}

TABLE III. Taguchi's L 9 Standard Orthogonal Array for UTS

\begin{tabular}{|c|c|c|c|c|c|}
\hline \multirow{2}{*}{ Trial Run } & \multicolumn{3}{|c|}{ Column } & \multirow{2}{*}{$\begin{array}{c}\text { UTS } \\
\text { (MPa) }\end{array}$} \\
\cline { 2 - 4 } & $\mathbf{1}$ & $\mathbf{2}$ & $\mathbf{3}$ & UTS \\
S/N Ratio
\end{tabular}


IOSR Journal of Mechanical and Civil Engineering (IOSR-JMCE)

e-ISSN: 2278-1684, p-ISSN: 2320-334X

\begin{tabular}{|l|l|l|l|l|l|}
\hline 4 & 2500 & 20 & 5.6 & 228.04 & 47.1602 \\
\hline 5 & 2500 & 30 & 5.8 & 231.60 & 47.2948 \\
\hline 6 & 2500 & 40 & 5.4 & 230.66 & 47.2594 \\
\hline 7 & 3500 & 20 & 5.8 & 225.60 & 47.0668 \\
\hline 8 & 3500 & 30 & 5.4 & 224.70 & 47.0321 \\
\hline 9 & 3500 & 40 & 5.6 & 229.50 & 47.2157 \\
\hline
\end{tabular}

\section{RESULTS AND DISCUSSION}

After conducting the experiments with different Settings of input factors i.e. Tool rotation speed, welding speed and tool pin length, the values of output variable (Ultimate tensile strength) were recorded and plotted as per Taguchi design of experiments methodology. The analysis of the results obtained has been performed according to the standard procedure recommended by Taguchi. The $\mathrm{S} / \mathrm{N}$ ratio is obtained using Taguchi's methodology. Here, the term 'signal' represents the desirable value (mean) and the 'noise represents the undesirable value (standard deviation). Thus, the $\mathrm{S} / \mathrm{N}$ ratio represents the amount of variation present in the performance characteristic. The values of $\mathrm{S} / \mathrm{N}$ ratio corresponding to different experimental runs have been tabulated in table 3 .

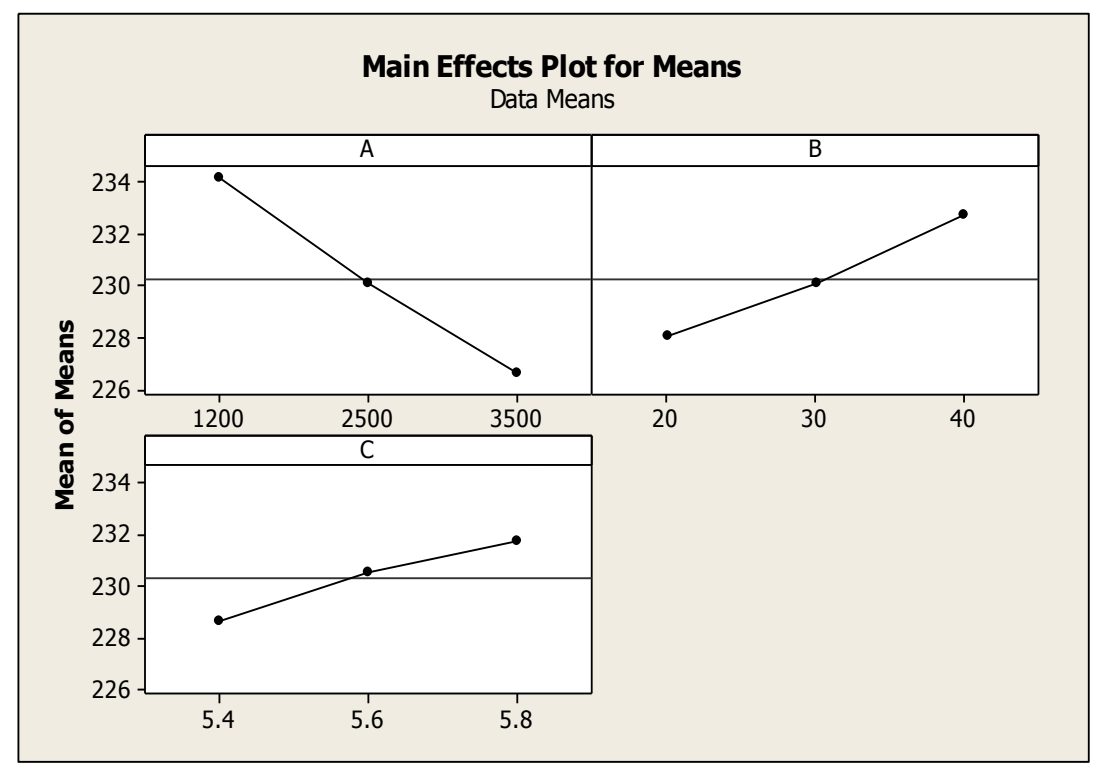

Fig.2: Effects of Process Parameters on UTS (Means)

TABLE IV. Response Table for UTS (Means)

\begin{tabular}{|c|c|c|c|}
\hline Level & A & B & C \\
\hline 1 & 234.2 & 228.0 & 228.6 \\
\hline 2 & 230.1 & 230.1 & 230.5 \\
\hline 3 & 226.6 & 232.8 & 231.8 \\
\hline Delta & 7.6 & 4.7 & 3.2 \\
\hline Rank & 1 & 2 & 3 \\
\hline
\end{tabular}

The percentage contribution of various process parameters on the selected performance characteristic can be estimated by performing analysis of variance test (ANOVA) as shown in table 8. Thus, information about how significant the effect of each controlled parameter is on the quality characteristic of interest can be obtained. The results of response of ultimate tensile strength for mean are shown in Table 4. 
IOSR Journal of Mechanical and Civil Engineering (IOSR-JMCE)

e-ISSN: 2278-1684, p-ISSN: 2320-334X

TABLE V. ANOVA for UTS (Means)

\begin{tabular}{|c|l|l|l|l|l|l|}
\hline Source & DF & Seq SS & Adj SS & Adj MS & F & P \\
\hline A & 2 & 86.664 & 86.6641 & 43.3320 & 315.73 & 0.003 \\
\hline B & 2 & 33.582 & 33.5820 & 16.7910 & 122.34 & 0.008 \\
\hline C & 2 & 15.201 & 15.2006 & 7.6003 & 55.38 & 0.018 \\
\hline Residual Error & 2 & 0.274 & 0.2745 & 0.1372 & & \\
\hline Total & 8 & 135.721 & \multicolumn{5}{|l}{} \\
\hline
\end{tabular}

It can be observed from figure 2 that the Tool rotation speed affects the Ultimate Tensile strength very significantly. From the figure 2, the highest Ultimate Tensile strength has been recorded with tool rotation speed (at level 1), welding speed (at level 3) and tool pin length (at level 3). It is also clear from the figure that the UTS increase as the welding speed is increased. But with the increase of tool rotation speed the UTS found to be decreased.

With regarding to the $\mathrm{S} / \mathrm{N}$ response, the values of $\mathrm{S} / \mathrm{N}$ ratio have been found to be highest for those factor levels that correspond to highest average response. Hence, these factor levels can be termed as optimum from the point of view of average response as well as $\mathrm{S} / \mathrm{N}$ response. As $\mathrm{S} / \mathrm{N}$ response takes into account both the magnitude as well as the variation in response, the factor levels that correspond to highest $\mathrm{S} / \mathrm{N}$ ratio are termed as optimum. The analysis of results showed that " $\mathrm{A}_{1} \mathrm{~B}_{3} \mathrm{C}_{3}$ " is the optimal parameter setting for the Maximization of UTS. Hence, it can be concluded from this discussion that "input parameters settings of tool rotation speed at 1200RPM, welding speed at $40 \mathrm{~mm} / \mathrm{min}$ and tool pin length at $5.8 \mathrm{~mm}$ have given the optimum results for UTS; in Friction stir welding on AA 6082-T6.

\section{CONCLUSION}

Basically, this study evaluates the welding performance of friction stir welding by using vertical milling machine on aluminum alloy $6082 \mathrm{~T}-6$. All the experiments trials, planning and analysis were executed using Taguchi design of experiment. The purposes of DOE method applied in this study were to determine the optimum condition of welding parameters and the significance of each parameter to the performance of welding characteristics. The total experiment runs performed in this study was nine trials using randomized parameters which done by MINITAB 16 software.

The following conclusions are drawn based on the performance of welding characteristics studied in this research work namely, Ultimate tensile strength (UTS):

1. All the selected parameters i.e. Tool rotation speed, welding/transverse speed and tool pin length significantly affect the Ultimate tensile strength in Friction stir welding on AA6082.

2. With regarding to the average response, Tool rotation speed has emerged as most significant parameter and Welding speed is the second significant parameter. And tool pin length can be termed as less significant for Ultimate tensile strength.

3. it can be concluded from the result that input parameters settings of tool rotation speed at 1200RPM, welding speed at $40 \mathrm{~mm} / \mathrm{min}$ and tool pin length at $5.8 \mathrm{~mm}$ have given the optimum results for UTS; in Friction stir welding on AA 6082.

\section{REFERENCES}

[1] M Ericsson, and R Sandstro, Influence of welding speed on the fatigue of friction stir welds and comparison with MIG and TIG. International Journal of Fatigue, 25, 2003, 1379-1387.

[2] J Adamowski, C Gambaro, E Lertora, M Ponte, and M Szkodo, Analysis of FSW welds made of aluminium alloy AW6082-T6. International Scientific Journal, 28, 2007, 453-460.

[3] HS Patil, and SN Soman, Experimental study on the effect of welding speed and tool pin profiles on AA6082-O aluminium friction stir welded butt joints, International Journal of Engineering, Science and Technology, 2, 2010, 268-275.

[4] G Raghu Babu, KGK Murti, GR Janardhana, An experimental study on the effect of welding parameters on mechanical and microstructural properties of AA 6082-t6 friction stir welded butt joints, Asian Research Publishing Network, 3, 2008, 1819-6608. 
[5] A Scialpi, LAC De Filippis, P Cavaliere, Influence of shoulder geometry on microstructure andmechanical properties of friction stir welded 6082 aluminium alloy, Materials and Design, 28, 2007, 1124-1129.

[6] N Sharma, R Khanna and RD Gupta, Multi Response Optimization of WEDM Process Parameters with RSM, Procedia Engineering, 64, 2013, 710-719.

[7] N Sharma, A Singh, R Sharma, and Deepak, Modelling the WEDM Process Parameters for Cryogenic Treated D-2 Tool Steel by integrated RSM and GA. Procedia Engineering, 97, 2014, 1609-1617.

[8] N Sharma, N Ahuja, S Gupta, A Singh, and R. Sharma, Modeling and Parametric Investigation of WEDM for D-2 Tool Steel Using RSM and GA. Applied Mechanics and Materials, 592-594, 2014, 511-515.

[9] N Sharma, T Raj, KK Jangra, Parameter Optimization and Experimental Study on Wire Electrical Discharge Machining of Porous Ni40Ti60 alloy. Proc. IMechE Part B: Journal of Engineering Manufacture, 2014. doi:10.1177/0954405415577710.

[10] N Sharma, R Khanna and RD Gupta, WEDM Process Variables Investigation for HSLA by Response Surface Methodology and Genetic Algorithm. Engineering Science and Technology: an International Journal, 18 (2), 2015, 171-177. doi:10.1016/j.jestch.2014.11.004.

[11] R Khanna, and H Singh, Performance analysis for D-3 material using response surface methodology on WEDM. Int. J. of Machining and Machinability of Materials, 14, 2013, $45-65$.

[12] P Gupta, R Khanna, RD Gupta and N Sharma, Effect of process parameters on overcut in WEDM for HSLA using response surface methodology. Journal of engineering and technology, 2, 2012, 1-6.

[13] N Sharma, R Khanna, RD Gupta, and R Sharma, Modeling and multi response optimization on WEDM for HSLA by RSM. Int. J. Adv. Manuf. Technol., 67, 2013, 2269-2281. 